\section{As novas tecnologias da informação e o consumismo em saúde}

\author{
New information technologies \\ and health consumerism
}

\begin{abstract}
Concepts related to consumption have shifted to include social processes not previously covered by traditional categories. The current review analyzes the application of classical concepts of consumerism to practices recently identified in the health field, like the phenomenon of cyberchondria. The theoretical challenge relates to the difficulty in extrapolating from the economic perspectives of consumerism to self-care issues in the context of information and communication technologies (ICTS). Drawing on recent anthropological categories, the study seeks to understand the phenomenon of self-care commodification under the imperative of self-accountability for health. New consumer identities are described in light of the unprecedented issues concerning technical improvements currently altering the nature of self-care. The study concludes that health is consumed as vitality, broken down into commercial artifacts in the context of a new bioeconomy - no longer linked to the idea of emulation and possession, but to forms of self-perception and self-care in the face of multiple risks and new definitions of the human being.
\end{abstract}

Consumer Health Information; Self Care; Internet
Paulo Roberto Vasconcellos-Silva 1,2 Luis David Castiel 2 Marcos Bagrichevsky 3 Rosane Harter Griep 4

\section{Introdução}

Há notórios sinais de crescente e inexorável influência das Tecnologias de Informação e Comunicação (TIC) nas questões da saúde. Diversos estudos têm registrado a relevância da Internet nesse campo 1, chegando a proporções que variam entre $80 \%$ dos adultos nos Estados Unidos e $66 \%$ dos europeus a consumir informações sobre saúde na grande rede 2 . Proliferam os estudos que apontam para a Internet como valioso recurso ao auto-cuidado, provendo informação e promovendo interação entre profissionais, cuidadores e usuários na condição de padecimentos crônicos ou de simples interessados nas questões da saúde humana 3,4,5,6. Um grande inquérito, envolvendo 4.764 usuários, tem resultados mais convincentes a exibir: cerca de um terço dos "consumidores de informação" admitia que a Internet interferisse genuína e definitivamente em suas decisões capitais no campo da saúde 7 .

Embora tal recurso goze de crescente credibilidade entre seus usuários 8 , o crescente afluxo na direção das tecnologias de informação em saúde tem suscitado questionamentos sobre a isenção de propósitos de seus patrocinadores em vista do grande número de sítios de qualificação duvidosa 9,10. Mesmo à frente de fontes questionáveis, o interesse público se intensifica e as tecnologias que buscam por qualidade de informação se sofisticam, encorajadas por um aparato co- 
mercial de crescente influência nessa área de produção 6 e por entusiastas do empowerment dos consumidores 4,11,12. Os ideais do "consumerism" alcançam uma faixa cada vez maior de atividades do governo, empresas e organizações independentes, o que se reflete nitidamente na disseminação dos sites sobre saúde direcionados à população leiga 9,12. Há preocupações em proteger os consumidores das fraudes e das práticas que violem seus direitos, assim como garantir o acesso à informação que possibilite as melhores decisões 12,13. Sob as forças do mercado livre que reinam soberanas nesses campos, o poder (ou empowerment) do consumidor é tido como ícone-síntese das vitórias asseguradas pelos valores liberais mais elevados, ao lado dos direitos civis e da democracia.

Não obstante, o sentido do termo consumismo não é unívoco. Tomá-lo como se estivesse em questão uma mesma essência que envolve tanto a aquisição frívola de bens como o exercício de um direito inalienável faz perder de vista vários desdobramentos sócio-antropológicos que têm a nos ofertar tanto material para análises. Um aspecto a enfatizar é o que se poderia chamar de fenômeno de "colonização do simbólico" ou, como denominado por Jameson 14, a "dominação do inconsciente" produzida pelo marketing a serviço das forças criadoras do capitalismo contemporâneo. O universo simbólico se entrelaçou ao universo produtivo redefinindo novas categorias como "sociedade do entretenimento" 15 , ou "do espetáculo" 16. O marketing tem abundante material a coletar nos artefatos produzidos pela indústria cultural, que se tornaram centros de referência do capitalismo. Na modernidade líquida contemporânea, percebemos a aceleração do tempo e a desterritorialização pela implosão das formas produzidas 17 que geraram as condições de instalação de um capitalismo de acessos a experiências 18 , nascido da expansão do conceito de aquisição, posse e usufruto de bens. $\mathrm{O}$ valor atribuído às coisas do mundo, fundamento do contrato social moderno, transcendeu aos sacos de algodão, caixotes de laranja e minas de carvão da época de Marx. Cada vez mais experiências atreladas aos produtos são comercializadas. No nível das massas, consumidores se convertem em produtores de valor no moto contínuo das relações de acesso substitutivas da propriedade. À medida que aderem, adotam ou consomem, também contribuem para reafirmação de tendências que pouco têm a ver com o valor de uso ligado aos bens. Além de artefatos concretos, vende-se atualmente o acesso ágil à informação orientada pelos desejos, medos e paixões mais profundas, a seguir devolvidas à materialidade sob a forma de fetiches.
Além do consumismo amiúde associado à idéia de compra frívola, é necessário distinguir no horizonte pós-moderno, sobretudo nos férteis campos da saúde, o consumismo por acesso a estatísticas, novas descobertas e resultados de pesquisas sobre terapias e panacéias de toda sorte na qualidade de produtos culturais intensamente divulgados pelas mídias. Há quem identifique entre os usuários contumazes dos sítios sobre saúde a presença de um crescente grupo de proto-pacientes 19 intimidados à lógica do mainstream da biomedicina - o que parece coincidir com a expansão dos sites de auto-diagnóstico 20,21 em um contexto de hiper-oferta de informações em saúde. Em um campo diametralmente oposto, existe a tribo dos críticos resistentes às verdades médicas, que erigem suas predileções de consumo em saúde à imagem de suas cosmovisões leigas 19. Estes alternam comportamentos, oscilando entre aceitação e rejeição das verdades que lhes são apresentadas neste jogo 22 . Vale acrescentar que ambas as tipologias parecem guardar alguns traços em comum - um oscilar permanente entre um self racionalizador, persistentemente conectado à idéia de administração da própria saúde à distância dos riscos e um outro, seu oposto, assombrado por medos, tabus e crenças fundadoras. Interessante observar que no terreno dos discursos públicos, as vozes de usuários soberanos e cibercondríacos se fundem no mesmo clamor por qualidade e isenção das fontes na Internet.

Sob tais perspectivas, pergunta-se: pelas lentes antropológicas, haveria um significado ordenador, coletivamente disseminado como elemento cultural, a partir do qual as idéias de consumismo de informações em saúde articularse-iam a uma visão de mundo? O consumismo em saúde em articulação com as TICs é aqui admitido como relevante objeto de estudos na medida em que expressa aspectos peculiares aos nossos conceitos acerca do que é imprescindível saber para cuidar-se. A que somos vulneráveis, a que riscos nos expomos e o que devemos saber para prolongar a vida e fazer para sanar nossos males e desconfortos? O conceito do que constitui nossa saúde se insere em um processo no qual o poder que os objetos adquirem se correlacionam com interiores exteriorizados, perenemente ligados às coisas constituintes de si. Os indivíduos em suas práticas de auto-cuidado, se submetem a artefatos, prescrições e interdições, regimes de economia calórica e terapias através dos quais conseguem se ver e se identificar, embora, nesse percurso, reduzindo-se a consumidores. Nesse contexto como compreender o consumo em saúde sob as perspectivas dos textos clássicos - práticas de marcação social ou estratégias de inclu- 
são? Decerto, em vista da proliferação de estudos antropológicos que tendem a se ocupar desses assuntos 23 , tais terrenos virão a oferecer material rico em análises de sistemas culturais emergentes, ainda pouco estudados nesses domínios.

\section{O consumismo e o mercado livre}

Há ampla documentação acerca da evolução histórica do espírito do consumerism que estrutura sistemas de saúde americanos e europeus, suficientemente analisada sob variadas perspectivas 24 . No debate da alocação de recursos públicos em saúde, parece haver um ambiente político-econômico-cultural amplamente favorável à tal racionalidade 25 . A leitura de um documento chave no contexto do National Health Service (NHS) inglês 26 nos faz acreditar que a escolha de profissionais e instituições deveria se pautar, como em qualquer tipo de mercado, pelo exercício da liberdade e da informação qualificada à frente de um rol de alternativas acessíveis. Assim organizado, o sistema seria habitado por médicos e hospitais que atendessem melhor as demandas de seus consumidores como legítimos agentes sociais a confiar sua saúde àqueles que melhor lhes satisfizessem as demandas. No universo do mercado livre, tudo funcionaria com base na motivação, informação e livre decisão dos clientes-consumidores, não importando se se deseja escolher um bom restaurante, contratar um mecânico de automóveis qualificado ou um dermatologista competente.

Atualmente a literatura sobre o tema se divide entre os (hegemônicos) apologistas do mercado livre e do consumismo e aqueles que não vêem a idéia como uma panacéia para os problemas administrativos. A complexidade que circunda o tema cresce sobremaneira quando se lhes acrescenta o aspecto da percepção dos direitos do consumidor. Quando as prerrogativas ao uso do sistema entram em jogo, os usuários parecem oscilar entre rainhas soberanas e peões passivos 22,24, reclamando ou acatando as condições que lhes são impostas neste jogo.

Sob a ótica do consumismo dos peões frívolos, a saúde pública passaria a ser constitucionalmente designada como provedora de acesso irrestrito ao usufruto de bens e serviços tão mais dispendiosos quanto alienados de sua utilidade social. Sob tais perspectivas, restaria ao poder público do Estado mínimo neoliberal - como materialização da nossa consciência política, ou da falta desta - a defesa de nosso patrimônio-saúde pela facilitação ao acesso às sofisticadas terapias. O Estado, que promove ações de prevenção do câncer imprimindo meramente as advertências nas embalagens de cigarro, se tornaria algo externo a nós, uma entidade sem a inscrição de nossos rostos e sem a direção de nossas aspirações em uma sociedade com direito à irrestrita medicalização pelo consumo de futilidades.

As mídias de massa revigoram cotidianamente um conceito diretamente ligado à lógica da auto-responsabilização em saúde - o empowerment individual - na crença de que, pelas vias do consumismo, o somatório de nossas saúdes individuais se prestaria à promoção de uma sociedade sadia 27. O mecanismo de produção de tais sentidos se potencializa em nosso país na aposição do conceito de saúde como bem de consumo coletivo e universalização do acesso aos serviços (contextualizado sob perspectivas políticas de democratização da saúde) enfocados pela mídia como direito de todos ao acesso individual à sua saúde em particular. Desconsidera-se, assim, a dimensão que implica inúmeras outras ações a desenvolver pelo intermédio de mobilização da sociedade civil organizada e a participação popular 27. A ênfase se afasta da co-responsabilização, do desenvolvimento de estratégias de articulação entre profissionais da saúde e população em vista de maior controle sobre suas condições de vida nos níveis individual e coletivo.

Não obstante à confiança na "mão invisível do Mercado" há trabalhos recentes que apontam para algumas ambigüidades. Estaria o paradigma do mercado livre a obscurecer (paradoxalmente) a autonomia dos pacientes em suas escolhas? Downie 28 aponta para uma progressiva substituição do princípio da autonomia pelo apelo do consumismo, que deslocaria o locus de responsabilidade das ações para o consumidor. O médico, esvaziado de alguns dos valores éticos que lhe governam o ofício, assumiria um papel estritamente técnico, de parecerista, ao abandonar seu papel de conselheiro nos pactos terapêuticos. Parece-nos que o consumismo tem se tornado campo fértil para as crescentes tensões entre necessidades (por vezes conflitantes) de sua clientela, além de incitar às temerárias práticas do auto-diagnóstico de eficácia questionável 21. Por um lado, estimula-se a competição entre os melhores experts e as tecnologias diagnóstico-terapêuticas mais avançadas em um mercado livre presidido pelos direitos dos consumidores. Por outro lado, talvez o espírito do capitalismo nos "sensualistas sem coração" circundados pelos melhores "experts sem espírito" 29 a lhes orientar na rota de suas expectativas, sintam-se solitários colonizadores de nichos desabitados, sob montanhas de informações técnicas coletadas ao longo de um sinuoso processo de cuidado de si. Seriam os ideais da "medicina centrada no paciente" 30 de difícil articulação com os ideais da "medicina 
centrada no consumidor"? Em síntese, ao contrário de uma conotação pejorativa, remetendo à frivolidade e ao desperdício nas aquisições, o consumerism adquire um nobre sentido, síntese de valores das sociedades nas quais há sistemas culturais fortemente orientados à produção e à acumulação de capital.

Sob perspectivas antropológicas, o fenômeno do consumismo no campo da saúde e da doença se traduz em várias direções. A índole individualista da sociedade de mercado demonstra aí seus mecanismos lacunares de reprodução e comunicação social. No consumismo revela-se a cultura da acumulação material, da cidadania expressa na linguagem do consumidor e da valorização da liberdade de escolha na aquisição das novidades como bens, serviços e informação.

\section{História do consumismo - o consumo da emulação}

Embora os estudos sobre o fenômeno do consumo tenham proliferado nos últimos tempos 31 , ainda está por ser refinada uma teoria absoluta e totalizante que dê conta de seus tantos aspectos multifacetados. Por que, afinal, adquirimos tantas peças desnecessárias, cobiçamos tanto artefatos de grife ou nos envolvemos com determinados tratamentos e regimes de contenção que surgem (ou ressurgem) do nada, acenando com benefícios de natureza imaterial e intangível? Que mola propulsora movimentaria o ciclo da A.I.D.A. 32 - chamar a Atenção, gerar Interesse, Desejo e, finalmente, Ação (como Aquisição) nos terrenos do auto-cuidado? O consumo atenderia a alguma necessidade humana primordial de natureza psíquica socialmente partilhada? Seríamos reféns eternos de uma índole essencialmente inclinada à cobiça, posse e exibição de artefatos ou à espera da anunciação de perigos que prenunciem a morte ou a decrepitude? Ou haveria pulsões ou instintos individuais acolhidos e consagrados pelo coletivo ou existiria, no sentido oposto desta mesma direção, uma objetificação de sujeitos em vil engendramento com a subjetivação de objetos?

Hannah Arendt destacava, acerca do conceito de consumismo, que as coisas do mundo moderno haviam se tornado produtos do labor, cujo destino natural é o mero consumo em lugar dos produtos do faber/trabalho, essencialmente destinados ao uso ${ }^{33}$. Sob tais perspectivas, o Homo faber, fabricante de bens duráveis, passou a se perceber como animal laborans, produtor de objetos feitos para serem rapidamente descartados, adaptando, assim, o poder de compra individual ao ritmo da produção. Sob tais perspectivas, com a extinção do Homo faber e da utilidade das coisas, esvaziou-se o valor que legitimava o esforço humano para fabricar artefatos duradouros. O consumo se tornou servo substancial da felicidade - não mais se trataria da aquisição de um produto de utilidade como um fim em si, mas a própria venda. Em outros termos, a sociedade de consumo se definiria não pelo seu alto grau de consumismo, mas pela desarticulação deste com qualquer função instrumental, como fim autopropulsor ${ }^{34}$.

A partir de circunstâncias históricas surgem os horizontes culturais de uma sociedade hiperofertada em termos de bens, que prescinde amplamente do sujeito produtivo e acumulador. Após dois séculos de capitalismo (e extraordinariamente impulsionados a partir na metade final do século XX) emergem princípios e valores configurados na reformulação de conceitos de felicidade e relações de trocas que, ora fornecem indícios de desagregação 34 ou desintegração social 35 , ora parecem essenciais às construções identitárias em um contexto de transformação da estrutura atrativa do hedonismo moderno 36 . Sob tais horizontes, se radicam no interior sentimental, a projetar peculiaridades emocionais na vacuidade de um romantismo outrora perdido 36 , colocando algo de seu caráter permanente e interior nos objetos comprados e exibidos - forma de produção material de crenças emocionais ou, como em Bourdieu 37, a busca pela distinção como mecanismo de manutenção de relações sociais de dominação. Em síntese, sob as lentes lacanianas, consumir - como sinthoma - "é terse, no lugar onde se encontra a falta do Outro" colocar-se algum objeto para localizar, por meio dele, sua própria falta de um objeto de gozo 38 .

\section{Consumo e ordenação social}

Na dimensão do social marxista, o fetichismo da mercadoria estaria ligado à ilusão de um " $f a l$ so saber", o ocultamento de uma verdade a ser descoberta, uma aleivosa consciência a emancipar das ideologias opressoras. Na dimensão dos frankfurtianos, sob a contextualização de um paralelo entre Marx e Freud, a subjetividade estaria submetida a um formato social fetichista, no enquadramento de uma "perversão total da cultura" 39. Não obstante, o reconhecimento do consumismo como fenômeno complexo e multifacetado perante as novas TICs envolveria a reformulação de alguns conceitos frankfurtianos sobre a indústria cultural. Em Adorno esta se colocaria como produtora-mor de um feixe homogêneo de crenças que neutralizariam a individualidade e a criatividade na direção da referida 
cultura "pervertida" como mercadoria 39. Nesse contexto, o marketing seria uma "psicanálise às avessas" ao fetichizar as paixões e temores, neutralizando todo o desejo e, em última instância, o próprio sujeito.

Em meados dos anos 70, em plena era da condenação moral da aquisição de bens por frivolidade a serviço da produção capitalista, a antropóloga Mary Douglas e o economista Baron Isherwood 40 postulam perguntas em direções precisas e inauditas. Como é da natureza dos bons estudos interdisciplinares, evitam o senso comum (assim como a ética da frugalidade marxista contra a emulação capitalista) e se debruçam sobre a questão: por que consumidores compram bens? A partir de Douglas \& Isherwood a teoria do consumo passaria a ser vista como uma teoria da vida social, como rica gramática para compreender o texto cultural. A Economia é acionada por Isherwood na direção da crítica à teoria da demanda - centro da Economia como disciplina - incapaz de responder à questão assim colocada. O consumidor já havia saído do domínio da necessidade, mas, ao pender para o lado frívolo da aquisição, tornar-se-ia semi-irracional? A teoria do consumo conspícuo de Thorsten Veblen - motivações ligadas exclusivamente ao copiar de gostos das classes altas - embora avançando sobre a teoria utilitária para sustentar que o consumo adquirira significação social, ainda seria uma idéia generalizada e simplista dos jogos de emulação.

Os bens de consumo seriam instrumentos de comunicação de categorias culturais e valores sociais, tornando tangíveis e estabilizando tais categorias - “a função essencial do consumo é sua capacidade de dar sentido" 40 (p. 108). As escolhas de consumo refletem julgamentos morais e valorativos - o jogo da emulação - dizem algo sobre o sujeito e sua rede de relações. $\mathrm{O}$ ato de consumir seria necessário à definição, afirmação e redefinição de categorias sociais. Ir além do uso prático dos bens seria, para Douglas \& Isherwood, perceber as escolhas como formas de classificação e o consumo como um ato ritual - talvez não apenas na qualidade de meras mensagens mas, talvez, como elemento estruturante no próprio sistema.

\section{Consumo e vitalidade}

Sob tais perspectivas, admitir o consumo em saúde como objeto de análise transcendente à dimensão instrumental do marketing a que se viu confinado envolve examinar o que governaria nossas escolhas entre regimes, exercícios, terapias e suas visões acerca do que é ser saudável, indo muito além da Atenção, Interesse, Desejo e Aquisição para necessidades ou caprichos 40,41. Além do consumismo, poucos fenômenos culturais articulam tantos artefatos e códigos na construção de categorias que nos falam de estilos e concepções de vida norteadores de projetos pessoais e coletivos. Partindo de tais contextos, poderíamos nos referir à busca pelo acesso obsessivo por informações sobre saúde como uma espécie de consumismo para vitalidade? No cenário em questão, a vitalização parece se aproximar mais de sua faceta quantitativa do que qualitativa, mais ligada à postergação do que à tonificação. Vitalidade não para imprimir vigor ou força vital, mas para ampliar o número de anos de existência pela redução de riscos à saúde-não para acrescentar vida aos nossos dias e sim para somar dias às nossas vidas.

Tais perspectivas são enriquecidas por Nikolas Rose, fundamentado no conceito de biopolítica e re-engenharia biológica da vitalidade 42 . $\mathrm{Na}$ instituição e consagração de tecnologias, haveria a necessidade de reconfiguração de formas de vida assim como a remodelagem de um pequeno corpo de técnicas requisitado como dispositivo, como práticas de si orientadas por artefatos de comunicação, como a Internet 43 . Nesse cenário as tecnologias médicas atuais não teriam como objeto somente o controle de doenças, mas também o de processos vitais pelo intermédio das "tecnologias de vitalidade". Se a causa primordial da medicina era a batalha contra a anormalidade em busca da norma vital normal, agora observamos tais normatividades se reconfigurando para otimizações, indo além do aperfeiçoamento da saúde pelas dietas e fitness. Colocam-se agora outras questões acerca da expectativa do que é ser um organismo biológico mediado por drogas do desejo e das vaidades, reprodução assistida, transplantes de órgãos, aprimoramento genético etc. A biotecnologia modificaria a idéia do humano, colocando o envelhecer quase como uma opção a mais para consumidores. Não se trataria mais de saúde, mas de vida, vitalidade, a ser decomposta em uma série de objetos diferentes por estabilizar, armazenar, trocar e comercializar em distintos contextos e empreendimentos bioeconômicos 42 . Rose propõe a discussão da bioeconomia - capitalização da vitalidade e do biocapital nos fluxos econômicos da vitalidade. Tais fluxos seriam tracionados persistentemente pelos circuitos farmacêuticos transnacionais, entre outros, com espaços de divulgação assegurados pelas mídias. O consumismo em saúde na Internet seria, sob tais perspectivas, uma faceta dos circuitos do biocapital. Nestes, a idéia de risco se insinuaria persistentemente 44 , a cobrar as dezenas de decisões prosaicas que se nos apresentam 
ao ritmo de nosso dia-a-dia, cada vez mais administrado pelas prescrições especialistas.

Colocado sob tais lentes, como encaixar o consumismo de informações em saúde como modalidade de classificação social, como totemismo ordenador de diferenças na cultura contemporânea? À leitura de Douglas \& Isherwood 40 , haveria como categorizá-lo como fenômeno cultural e simbólico pela prevalência de sua função significacional no exercício de uma nova vocação classificatória? Ou, por outro lado, ao abandonar a idéia de ordenação social, estaria o consumo em saúde a nos revelar uma forma de íntima "ordenação de si", não mais ligada à idéia de distinção e sim a novas formas de perceber-se e cuidar-se frente às novas ameaças oferecidas pela sociedade do controle 45 ?

Indo além do biopoder, estaria a idéia de consumismo em saúde ligada a formas de autopreservação norteada por expectativas ou medos pessoais que se retroalimentam na Internet 1,46 e se justificam como fim em si ao qual nos referimos genericamente como auto-cuidado? Entre os múltiplos conceitos sobre consumismo, haveria convergência de elementos semi-ocultos a nos revelar sentidos até aqui mal identificados? A referida ordenação de si, ligada à vitalidade e à postergação da existência, assumiria de algum modo uma função identitária, como forma de auto-definir-se no processo do auto-cuidado?

\section{Sínteses}

\section{Primeira: mudanças nos objetos de desejo}

O desenvolvimento da idéia de consumo para vitalização envolve uma dupla perspectiva, ligada tanto à desmaterialização dos objetos de consumo quanto às necessidades redimensionadas dos sujeitos consumidores. Cabe reconhecer, primeiramente, a ampliação da natureza dos objetos passíveis de consumo no processo de "perda de substância" do mundo dos bens. Houve uma rápida transição aos sistemas econômicos imateriais nos quais circulam incessantemente as experiências de acesso à informação e ao entretenimento ${ }^{18}$. Antes ligados à produção de bens, agora associados também a uma nova macroeconomia desmaterializada de um núcleo de produtos concretos, livres de vinculação com objetos particulares e aptos a serem usados em associações múltiplas. O consumo da experiência não é novidade recente, posto que nas origens da indústria cultural a mercadoria se reformatou no acesso às experiências de gozo e fruição $47 \mathrm{e}$ no "uso dos prazeres" 48. Mediante o acesso ao valor da experiência, o que dá valor às coisas do consumo não é unicamente o suor necessário à sua materialização, como poderiam argumentar os marxistas, mas a saciedade de um desejo 49 ou a mitigação de um medo 50 . A novidade que aqui se identifica é a voracidade pelo autodiagnóstico sob os crescentes riscos oferecidos à atenção pública pelos modelos explicativos epidemiológicos e o stress social que neste campo são gerados 51 . No processo saúde-doença, sob as peculiares perspectivas individualistas, as "causas" para a ocorrência do caso são diversas das "causas" responsáveis pela incidência da doença 52 , ou seja, sob a cacofonia das mídias, as razões para a distribuição dos males e as condições de vulnerabilidade dos que deles adoecem são ainda obscuras ao senso comum 53 .

Baudrillard 54 aponta para uma extensa ampliação da autonomia do significado em relação ao significante a impulsionar a saturação de imagens em nossos horizontes culturais (inclusive na qualidade de mercadorias). A estetização/mercadorização dos "style packs" 34 e a superprodução de signos nos conduziu a uma inexorável perda de alguns de nossos significados mais estáveis, entre eles o da saúde e do cuidado. Imagens e signos cacofonicamente conjugados não acatam a ordenação e a coerência que as narrativas tradicionais têm a nos ofertar. O conceito de risco nas mídias é exemplo notório dos significados tão incongruentemente divulgados quanto avidamente consumidos por uma cultura hiper-ofertada de vozes dissonantes neste terreno 55.

Não obstante à hiper-oferta de significados, na vacância da mão divina, é perene a inquietação humana quanto aos destinos terrenos. As probabilidades de padecimento do corpo no futuro aquém-túmulo (e não mais as aflições da alma pecadora nas trevas) estão cada vez mais vinculadas às ações de vitalização e auto-cuidado no presente 56 . A interdição às frivolidades e fraquezas carnais - gula e preguiça - persiste como desafio cotidiano, ao qual se faz necessário reagir com a fé nas informações balizadas por estatísticas dos experts. Em meio à aparente polifonia das vozes especialistas, a seleção das melhores informações para as mais prosaicas decisões deveria ofertar a idéia de um futuro administrável e, dessa forma, mais seguro. Não obstante, estas vozes tendem a atrair seus devotos a uma espécie de círculo vicioso - mais informações acrescentam ansiedade suplementar no calvário cotidiano rumo à saúde perfeita em um futuro probabilístico.

\section{Segunda: mudanças nos sujeitos consumidores}

Em síntese, aos artefatos do desejo que outrora exerciam função de ordenamento social se as- 
sociaram outros, de natureza imaterial, transcendentes à sua substância na multiplicidade de novos significados. Na esfera do consumo das sensações oferecem-se sonhos e satisfação emocional individual pelo intermédio de múltiplos signos, imagens e mercadorias simbólicas 35 , mas também se oferece a sensação de controle sobre um futuro calculável na incerteza dos riscos. A crescente influência dos temas científicos ligados à saúde tem exibido uma sua faceta de novas, iminentes e nebulosas ameaças 57, da mesma forma que exibe sua outra face de perspectivas inauditas, como o aprimoramento genético da espécie, a ampliação da vida, a cura, a beleza e o prazer sem limites 56 . Assim, a idéia de saúde tem sido ofertada aos consumidores - seja na condição de proto-pacientes alinhados ou relutantes - como patrimônio administrável.

A saúde, a purificação do corpo, a cura de males, o equilíbrio ou o retorno às essências naturais desde sempre se incluíram no imaginário coletivo ligados a práticas e artefatos capazes de desencadear nos corpos e espíritos efeitos vitalizadores. Os mecanismos de validação de tais crenças se modificaram historicamente instalando-se nas culturas pelo pensamento mágico-religioso dos primórdios 58,59,60 ou nas mensagens tecno-científicas hodiernas disseminadas pelas TICs. Observa-se que estas últimas, em convergência com o pensamento neoliberal desviado em mercantilismo, têm se empenhado em associar a idéia de saúde a artefatos e serviços de consumo vicários 61 .

A fortalecer a presente tese, observa-se que a diluição de significados e efemeridade das verdades probabilísticas, conjugados ao rol crescente de ameaças à saúde (no casamento entre o jornalismo científico, epidemiologia e circuitos produtivos) têm fornecido material abundante para novas categorias. Com base em estudos de comunidades virtuais, têm sido descritas formações identitárias ligadas às escolhas neste campo. A partir da crescente influência cultural de assuntos ligados à ciência (a nos cobrar a todo o momento o consumo de informações para as melhores escolhas), surgem autores a identificar o nascimento de "identidades em saúde" 19. Tal fenômeno remete à diversidade e multiplicidade de relações de uma cultura industrializada, consumidora contumaz de artefatos tecnológicos e amplamente influenciada neste sentido pelo apelo midiático 19. Nesse contexto, há " $p a$ cientes-experts" cybercondríacos 62,63 alinhados e os dissidentes "consumidores em saúde". A diferença entre eles se nuclearia em uma espécie de divergência de fé - os primeiros, amplamente alinhados aos modelos explicativos biomédicos oficiais, consomem em larga escala todos os pro- dutos prescritos pelos sites e experts de maior credibilidade. Os "consumidores resistentes", ora exibindo ceticismo, ora excessiva credulidade, se apegam a modelos leigos de saúde, talhados à imagem de crenças e tabus peculiares que lhes norteiam as escolhas. Seja na rejeição ou afeição aos modelos explicativos hegemônicos, ambos buscam por vitalização no consumo de informações para exorcizar temores, controlar riscos, adotar regimes e equilibrar energias.

\section{Conclusões}

A pergunta desde sempre associada à condição humana é: quem somos, a que somos vulneráveis? Mais recentemente tem-se interrogado: o que consumir para prolongar e ampliar nossas limitações carnais? Na análise aprofundada do fenômeno do consumismo em saúde, torna-se necessário, além de reconhecer a ampliação/virtualização do mundo dos bens, observar as modificações ocorridas nas identidades dos sujeitos consumidores. Regimes dietéticos, planos de saúde, medicamentos, opiniões de experts, estudos epidemiológicos, cirurgias inovadoras, sites de informações e terapias alternativas são totemizados pelos eficientes propulsores das TICs e cada vez mais avidamente consumidos no circuito da bioeconomia da vitalidade. Segundo tal imaginário, artefatos e serviços de consumo efetivamente contêm saúde como espécie de síntese material da quimérica vitória do Homo sapiens oeconomicus contra a decrepitude e mortalidade inerentes à condição humana. Desde que consumidos sob condições de presumida morbidade e nas doses prescritas, tais artefatos induziriam seus usuários a estados de proteção e vitalidade pelo intermédio da transmissão da saúde "contida” nos produtos para o corpo vulnerável.

Em suma, além de produtos, consumimos nossos desejos e aspirações de reequilíbrio e a paliação de nossos temores sob concepções peculiares do universo no percurso de nossas existências. No decorrer de tal processo, os meios de comunicação popularizaram-se como instâncias legitimadoras do que é saudável e vital, disponibilizando discursos de autoridades qualificadas e textos redigidos por jornalistas especializados que se mesclam à cacofonia de mensagens comerciais pseudo-técnicas. Desta forma e por estes meios, a idéia de saúde é reificada e "individualizada" no somatório dos seus consumidores, esvaziando-se em suas dimensões sócioambientais e "fetichizando-se" utopicamente no aceno da vitalidade eterna ou na proteção contra riscos ao indivíduo. 


\section{Resumo}

Uma ampliação dos conceitos de consumo tem se deslocado na direção de processos sociais até agora não contemplados por categorias tradicionais. A presente revisão analisa a aplicação dos conceitos clássicos sobre consumismo às práticas recentemente identificadas no campo da saúde, como o fenômeno da cibercondria. $O$ desafio teórico se refere à dificuldade de extrapolação das perspectivas econômicas do consumismo às questões do auto-cuidado no contexto das tecnologias de informação e comunicação (TICs). Procura-se compreender o fenômeno da mercadorização do cuidar-de-si sob o imperativo da auto-responsabilização em saúde. São identificadas e descritas as novas identidades consumidoras em vista das inauditas questões acerca dos aprimoramentos técnicos a modificar a natureza do auto-cuidado. Conclui-se que a saúde é consumida como vitalidade decomposta em artefatos de comercializar no contexto de uma nova bioeconomia - não mais ligada à idéia de emulação e posse, e sim a novas formas de perceber-se e cuidar-se perante múltiplos riscos e novas definições do que é ser humano.

Informação de Saúde ao Consumidor; Autocuidado; Internet

\section{Colaboradores}

P. R. Vasconcellos-Silva contribuiu com a concepção, análise e interpretação dos textos e redação do artigo. L. D. Castiel, M. Bagrichevsky e R. H. Griep participaram da interpretação dos textos e revisão crítica relevante dos conteúdos; aprovação final da versão a ser publicada.

\section{Agradecimentos}

Este artigo foi financiado pelo Conselho Nacional de Desenvolvimento Científico e Tecnológico (CNPq/ MCT, edital no. 014/2008 - universal).

\section{Referências}

1. Vasconcellos-Silva PR, Castiel LD, Rivera FJU. Assessing an Internet health information site by using log analysis: the experience of the National Cancer Institute of Brazil. Rev Panam Salud Pública 2003; 14:134-7.

2. Pew Research Center. Health searches and email have become more common place, but there is room for improvement in searches and overall Internet access. http://www.pewinternet.org/ PPF/r/95/report_display.asp (acessado em 07/ Ago/2009).

3. Umefjord G, Hamberg K, Malker H, Petersson G. The use of an Internet-based Ask the Doctor Service involving family physicians: evaluation by a web survey. Fam Pract 2006; 23:159-66.
4. Kerr C, Murray E, Stevenson F, Gore C, Nazareth I. Internet interventions for long-term conditions: patient and caregiver quality criteria. J Med Internet Res 2006; 8:e13.

5. Tjora A, Tran T, Faxvaag A. Privacy vs usability: a qualitative exploration of patients' experiences with secure Internet communication with their general practitioner. J Med Internet Res 2005; 7:e15.

6. Sillence E, Briggs P, Harris P, Fishwick L. How do patients evaluate and make use of online health information? Soc Sci Med 2007; 64:1853-62.

7. Baker L, Wagner TH, Singer S, Bundorf MK. Use of the Internet and e-mail for health care information: results from a national survey. JAMA 2003; 289:2400-6. 
8. Mead N, Varnam R, Rogers A, Roland M. What predicts patients' interest in the Internet as a health resource in primary care in England? J Health Serv Res Policy 2003; 8:33-9.

9. Castiel LD, Vasconcellos-Silva PR. Internet e o autocuidado em saúde: como juntar os trapinhos? Hist Ciênc Saúde-Manguinhos 2002; 9:291-314.

10. Eysenbach G, Köhler C. How do consumers search for and appraise health information on the World Wide Web? Qualitative study using focus groups, usability tests and in-depth interviews. BMJ 2002; 324:573-7.

11. Verhoeven F, van Gemert-Pijnen L, Dijkstra K, Nijland N, Seydel E, Steehouder M. The contribution of teleconsultation and videoconferencing to diabetes care: a systematic literature review. J Med Internet Res 2007; 9:e37.

12. McMullan M. Patients using the Internet to obtain health information: how this affects the patienthealth professional relationship. Patient Educ Couns 2006; 63:24-8.

13. Jordan MA, Haywood T. Evaluation of internet websites marketing herbal weight-loss supplements to consumers. J Altern Complement Med 2007; 13:1035-43.

14. Jameson F. Pós-modernismo: a lógica cultural do capitalismo tardio. São Paulo: Editora Ática; 1996.

15. Gabler N. Vida - o filme: como o entretenimento conquistou a realidade. São Paulo: Companhia das Letras; 1999.

16. Debord G. A sociedade do espetáculo. Rio de Janeiro: Contraponto; 1997.

17. Bauman Z. Modernidade líquida. Rio de Janeiro: Jorge Zahar Editor; 2001.

18. Rifkin J. A era do acesso: a transição de mercados convencionais para networks e o nascimento de uma nova economia. São Paulo: Makron Books; 2001.

19. Fox N, Ward K. Health identities: from expert patient to resisting consumer. Health (London) 2006; 10:461-79.

20. Ryan A, Wilson S. Internet healthcare: do self-diagnosis sites do more harm than good? Expert Opin Drug Saf 2008; 7:227-9.

21. Vasconcellos-Silva PR, Castiel LD. As novas tecnologias de autocuidado e os riscos do autodiagnóstico pela Internet. Rev Panam Salud Pública 2009; 26:172-5.

22 Le Grand J. Motivation, agency and public policy: of knights, knaves, pawns and queens. Oxford: Oxford University Press; 2003.

23. Libin A, Libin E. Cyber-anthropology: a new study on human and technological co-evolution. Stud Health Technol Inform 2005; 118:146-55.

24. Greener I, Mills N. How did consumerism get into the NHS? An empirical examination of choice and responsiveness in NHS policy documents. http://www.consume.bbk.ac.uk/publications. html\#bookchapters (acessado em 01/Jul/2009).

25. Fox J. Consumerism 1: the different perspectives within health care. Br J Nurs 2003; 12:321-6.

26. Secretaries of State for Health, Wales, Northern Ireland and Scotland. Working for patients. London: Her Majesty's Stationery Office; 1989.

27. Marcondes WB. A convergência de referências na promoção da saúde. Saúde Soc 2004; 13:5-13.
28. Downie R, Randall F. Choice and responsibility in the NHS. Clin Med 2008; 8:182-5.

29. Weber M. A ética protestante e o espírito do capitalismo. São Paulo: Martin Claret; 2002.

30. Baarts C, Tulinius C, Reventlow S. Reflexivity - a strategy for a patient-centred approach in general practice. Fam Pract 2000; 17:430-4.

31. Rocha E. Expansão dos estudos de consumo. EcoPós 2006; 9:78-87.

32. Strong EK. Theories of selling. J Appl Psychol 1925; 9:75-86.

33. Arendt H. The human condition. Chicago: University of Chicago Press; 1958.

34. Bauman Z. Consuming life. Journal of Consumer Culture 2001; 1:9-29.

35. Featherstone M. Cultura de consumo e pós-modernismo. São Paulo: Studio Nobel; 1995.

36. Campbell C. A ética romântica e o espírito do consumismo moderno. Rio de Janeiro: Rocco; 2000.

37. Bourdieu P. La distinction: critique sociale du jugement. Paris: Les Editions de Minuit; 1979.

38. Santos TC. Sinthoma: corpo e laço social. Rio de Janeiro: Sephora/Universidade Federal do Rio de Janeiro; 2006.

39. Adorno TW, Horkheimer M. Dialética do esclarecimento. Rio de Janeiro: Jorge Zahar Editor; 1985.

40. Douglas M, Isherwood B. The world of goods: towards an anthropology of consumption. New York: Routledge; 2001.

41. Rocha E. A sociedade do sonho. Rio de Janeiro: Mauad; 1995.

42. Rose N. The politics of life itself. Biomedicine, power and subjectivity in the 21st century. Princeton: Princeton University Press; 2007.

43. Rose N. Powers of freedom. Cambridge: Cambridge University Press; 1999.

44. Beck U. Risk society: towards a new modernity. London: Sage; 1992.

45. Costa R. A sociedade do controle. São Paulo Perspect 2004; 18:161-7.

46. Vasconcellos-Silva PR, Castiel LD, Griep RH, Zanchetta M. Cancer prevention campaigns and Internet access: promoting health or disease? J Epidemiol Community Health 2008; 62:876-81.

47. Fontenelle IA. O trabalho da ilusão: produção, consumo e subjetividade na sociedade contemporânea. Interações Estud Pesqui Psicol 2005; 10:63-86.

48. Foucault M. História da sexualidade 2: o uso dos prazeres. Rio de Janeiro: Edições Graal; 1984.

49. Bauman Z. Comunidade: a busca por segurança no mundo atual. Rio de Janeiro: Jorge Zahar Editor; 2003.

50. Bauman Z. Liquid fear. Cambridge: Polity Press; 2006.

51. Castiel LD. O estresse na pesquisa epidemiológica: o desgaste dos modelos de explicação coletiva do processo saúde-doença. Physis (Rio J.) 2005; 15 Suppl:103-20.

52. Rose G. Individuos enfermos y poblaciones enfermas. In: Buck C, Llopis A, Nájera E, Terris M, editores. El desafío de la epidemiología: problemas y lecturas selecionadas. Washington DC: Organización Panamericana de la Salud; 1988. p. 901-9. (Publicación Científica, 505). 
53. Eastwood MR. Epidemiological studies in psychosomatic medicine. Int J Psychiatry Med 1975; 6: 125-52.

54. Baudrillard J. Sociedade de consumo. São Paulo: Elfos; 1995.

55. Vaz P, Pombo M, Fantiano M, Pecly G. O fator de risco na mídia. Interface Comun Saúde Educ 2007; 11:145-63.

56. Castiel LD, Alvarez-Dardet C. Saúde persecutória. Rev Saúde Pública 2007; 41:461-6.

57. Tulloch J, Lupton D. Consuming risk, consuming science - the case of GM foods. Journal of Consumer Culture 2002; 2:363-83.

58. Rocha E. Magia e capitalismo. São Paulo: Brasiliense; 1985.
59. Lévi-Strauss C. O pensamento selvagem. São Paulo: Edusp; 1970.

60. Lévi-Strauss C. O totemismo hoje. Petrópolis: Editora Vozes; 1975.

61. Donaldson C, Lloyd P, Lupton D. Primary health care consumerism amongst elderly Australians. Age Ageing 1991; 20:280-6.

62. Lewis T. Seeking health information on the internet: lifestyle choice or bad attack of cyberchondria? Media Culture Society 2006; 28:521-39.

63. Wickham S. The perils of cyberchondria. Pract Midwife 2009; 12:34.

Recebido em 10/Set/2009

Versão final reapresentada em 12/Mai/2010 Aprovado em 21/Jun/2010 